\title{
Causal fundamentality
}

\section{Soufiane Hamri ${ }^{1}$}

Received: 13 October 2021 / Accepted: 14 December 2021 / Published online: 18 February 2022

(c) The Author(s) 2022

\begin{abstract}
I present an argument for causal fundamentality, understood as the thesis that the causal history of every being, whose existence has a causal explanation, includes some uncaused beings. I argue that this thesis is a consequence of an actualist account of metaphysical modality whose novelty lies in its hybrid dispositional-essentialist foundation. I argue that my modal theory is extensionally correct and minimalistic. Its range of metaphysical necessities and possibilities is just as wide as needed to capture the pre-theoretical notion of modality. Moreover, my theory is immune from the necessitism of standard essentialist accounts of modality and addresses the challenge of global possibilities facing dispositionalist modal theories thanks to its essentialist component.
\end{abstract}

Keywords Causation · Fundamentality $\cdot$ Modality $\cdot$ Essence $\cdot$ Potentiality Dispositions · First cause

\section{Introduction}

Recent metaphysics has seen a growing interest in the question of fundamentality. As Bliss observes, "It is without question the prevailing view amongst contemporary analytic metaphysicians that there is something fundamental." (Bliss, 2019, p. 361). Fundamentality in the recent literature is intimately linked to the notions of grounding and ontological dependence that are usually taken as explanatory relations (Tahko, 2018). Grounding, for example, is widely believed to play an explanatory role. Fine writes, "We take ground to be an explanatory relation: if the truth that $P$ is grounded in other truths, then they account for its truth; $P$ 's being the case holds in virtue of the other truths' being the case." (Fine, 2001, p. 15).

The general idea behind the interest in fundamentality is that if reality, ordered by a certain explanatory relation, has a fundamental level, it is then possible to give, at

Soufiane Hamri

hamri.soufiane@gmail.com

1 Department of Philosophy, University of Birmingham, ERI Building, Edgbaston, Birmingham B15 2TT, UK 
least, a partial explanation of the existence of any given being, which would consist of a finite explanatory chain ending at something fundamental. ${ }^{1}$

The question that I would like to investigate is that of the existence of causally fundamental concrete beings whose existence does not have a causal explanation. This is an older question which is intimately related to that of worldview choice which is, arguably, one of the objectives of any systematic and complete metaphysical theory. For example, classical theistic worldviews position a concrete being, God, at the root of the causal order meaning that God is fundamental in terms of the causal relation. If it turns out that there are no ultimate causes, classical theism would be refuted.

A second motivation to choose causality as an explanatory relation of our investigation is to exclude the realm of abstract objects from the explanatory scope given that it is dubious that such objects can be said to exist or to be real in the ordinary sense of the term. It seems safe to deny that abstract objects have causal powers or can be relata of the causal relation. ${ }^{2}$ Setting abstracta aside, causation seems to be a legitimate explanatory relation to frame the question of fundamentality when the subject of enquiry is the world of our experience. Even if there are abstract beings, answering the question of the existence of ultimate concrete causes would still be an interesting task. Furthermore, on the supposition that abstract beings exist and that their existence is dependent on that of concrete beings, from which they are abstracted (Lowe, 2013), fundamental concrete beings, if there are any, would be fundamental tout court.

A third motivation to think in terms of causality is that grounding, ontological dependence and causality seem to share much in common when it comes to their formal properties. If one agrees with Wilson that grounding is a type of causation (Wilson, 2018), there seems to be reasonable prospects that the results of reasoning in terms of causation between concrete beings could be generalized to answer the question of fundamentality when the explanatory relation is grounding.

In what follows, I will argue that there are causally fundamental (uncaused) beings that are causal explanations of the existence of all other non-fundamental (caused) beings. ${ }^{3}$ Section 2 is dedicated to an outline of the notion of causality that will be used along with the account of modality on which the argument relies. Sections 3 and 4 are dedicated to the exposition of the argument and to a defence of its premises. Section 5 addresses an important objection to the introduced modal account and Sect. 6 concludes by highlighting the merits of the presented argument.

\footnotetext{
1 If the explanatory relation in question is well-founded in the sense that there are no infinite explanatory chains, it should then be possible to give a complete explanation of the existence of derivative beings in terms of finite explanatory chains that end with something fundamental.

2 Those who think that some abstract objects have causal powers can understand me as defining concrete objects as those that can enter into causal relations and abstract objects as those that are not concrete.

3 It is worth noting that the conclusion of my argument does not rule out the existence of infinite causal regresses.
} 


\section{Causation and modality}

The notion of causality that is of interest to my argument is that of efficient causation. An efficient cause $x$ of a given effect $y$ can be said to be responsible for $y$ 's existence through exercising a certain causal power that it has. We can define efficient causation as follows:

Efficient causation: $x$ is an efficient cause of another being $y$ i.e. $x$ causes $y$ if and only if $y$ 's existence depends on $x$ 's exercise of a certain power that it has.

The relata of the causal relation are concrete beings. This is different from the standard view according to which the relata of the causal relation are events (Lewis, 1986). While there seems to be a natural way to modify my definition of efficient causation by identifying as effects events consisting in the entry into existence of concrete beings and causes as the events consisting in the exercise of a certain causal power by other beings, I prefer to maintain my definition given that the notion of a being causing another being's existence seems perfectly coherent and that no gain in clarity or rigor is being achieved, for our current purposes, by introducing events explicitly in our framework. Moreover, my aim is to argue that there are causally fundamental beings that are causes of all other non-fundamental beings and not that there are causally fundamental events.

As is usually held in the metaphysics of causation, I assume that there is a counterfactual dependence between an effect's existence and it being efficiently caused by some being or other. This counterfactual dependence can be interpreted for our purposes as meaning that were an effect not caused to exist, it would not exist.

My definition of efficient causation embeds an irreflexivity condition. No being can be its own efficient cause. This seems to be beyond reproach if one acknowledges that existence is a pre-requisite for causal activity.

In addition to irreflexivity, it follows from my definition above that efficient causation is transitive and asymmetric. ${ }^{4}$ We can say that efficient causation is a strict partial order on the class $S$ of actual beings.

As my argument for causal fundamentalia will rely on modal notions, it is therefore of interest to outline the account of modality that is relevant to our purposes.

Metaphysical modality is about how things must be or could have been. Some philosophers take it that the way things must be depends on what those things are, on their essences (Fine, 1994). ${ }^{5}$ Others think that how things could have been depends on how they could behave or causally interact, which is determined by their powers, dispositions or potentialities (Borghini and Williams (2008); Vetter (2015)). For reasons that will soon become apparent, my own view is that both essences and (causal) powers have a central role to play in modal theorizing.

I understand causal powers in terms of abilities to act and participate in the evolution of the causal history of the world. I am now thinking about the argument that I want to defend, I have the power to do so. I take it that it was also open to me that I choose not

\footnotetext{
4 Transitivity follows from the transitivity of existential dependence. Asymmetry follows from the irreflexivity and transitivity of efficient causation.

5 I will use "essence" and "nature" interchangeably.
} 
to exercise that power and be, for example, currently thinking about where to spend my next holidays.

Assuming that there is causal contingency in the world, it seems that any modal theory that is not committed to the possibility of what actual beings could have brought about, by exercising their causal powers differently of how they actually did, is a nonstarter. Therefore, it is a minimal commitment of any plausible theory of modality that what actual beings could bring about by exercising their causal powers is possible. Moving beyond this minimal commitment to acknowledge genuine possibilities that all actual beings, past, present and future are collectively incapable to bring about no matter how they exercise their causal powers is unwarranted. Something non-actual that cannot be brought about cannot happen and is therefore impossible.

These considerations lead naturally to an actualist view about metaphysical possibility that is grounded in the causal powers of actual beings. Several actualist views of possibility have been recently developed to ground possibility on the dispositions or the potentialities that actual beings have (Borghini \& Williams, 2008; Vetter, 2015). Whether dispositions, potentialities and causal powers are the same notion or whether some of them can be reduced to others is beyond the scope of the current discussion. What is clear is that the three notions underlie ways in which beings could act. Given that we are interested in causal fundamentality, I will frame my account of metaphysical possibility in terms of causal powers while remaining neutral about the answer to the question of whether the resulting account could have been different if dispositions or potentialities were used instead.

Based on the foregoing discussion, the following definition of metaphysical possibility suggests itself:

Metaphysical possibility: a fact $F$ is possible if and only if $F$ obtains actually or there is some plurality $x x$ of actual beings with iterated causal powers to bring about the obtaining of $F$. $^{6}$

Iterated causal powers are understood as causal powers to bring about that there are causal powers to bring about something (with any finite number of iterations allowed). ${ }^{7}$ For example, assume that there is currently no computer with enough computational power to solve a certain type of mathematical equations that human beings lack to ability to solve by themselves. If it is within human power to build a computer that solves this type of equation, it is then possible that this type of equation is solved as a matter of humans having a causal power to bring about that there is something that has the power to do the needed task.

Note that the disjunctive form of the definition allows us to count as possible actually obtaining facts that no causal power enables to bring about. This secures, in its full generality, the widely accepted formal requirement that what is actual is possible. ${ }^{8}$

Finally, recourse to pluralities enables us to capture some possibilities that are not grounded in the causal powers of any given member of a certain plurality but are

\footnotetext{
6 'there is' in this definition should be understood timelessly. It can be substituted by 'there was, there is or there will be'.

7 The terminology of "iterated causal powers" mimics the iterated potentialities of Vetter (2015).

8 Yates (2015) used a similar definition to secure the formal adequacy of dispositional accounts of possibility.
} 
grounded in the causal powers of these members taken collectively, as in the example of some humans collectively having the power to build a certain type of computer even on the supposition that none of them is individually able to do so.

If we mean, as I think we should, by a metaphysically necessary fact one that cannot possibly fail to obtain, this account of possibility gives the following definition.

Metaphysical necessity (dispositionalist reading): a fact $F$ is necessary if and only if $F$ obtains and there is no plurality $x x$ of actual beings with iterated causal powers to bring about the non-obtaining of $F$.

Some philosophers are happy to end here, being satisfied with this definition of metaphysical necessity. Leftow, for example, thinks that this definition ensures that the necessity of necessary facts is not grounded in anything given that it is a matter of absence of causal powers to bring about the non-obtaining of the concerned facts. Absences being nothing, Leftow concludes that the necessity of necessary facts comes for free as a desirable feature of his modal theory (Leftow, 2017).

I think that one can move forward to identify what is about actual beings that grounds the absence of causal powers to bring about the non-obtaining of necessary facts. Such a ground would be a ground of the necessity of these facts. Where, then, to look for such a ground? I suggest that this ground is to be found in the essences of (some) beings.

I understand essence in the sense of real definition. The essence of something is what it is to be that thing or what that thing is. As Hale puts it "a definition in the relevant sense is of the thing, rather than of a word standing for the thing" (Hale, 2018, p.126). I am sympathetic to the view that a real definition captures what has come to be known as the constitutive essence of the thing that it defines, which includes the most basic features of the thing that cannot be accounted for by other more fundamental features of it (Rosen, 2015).

Until recently, the classical view about essence was that essence is analysable in terms of metaphysical necessity. On this view, i.e., classical modalism as described by Torza (2015), a being $x$ has a certain property $P$ essentially if and only if it is necessary that $x$ has $P$ if it exists (Torza, 2015, p. 757).

In his celebrated paper "Essence and modality" (Fine, 1994), Fine presented a series of counterexamples to classical modalism. I join Fine in thinking that he has shown that essence is a more fine-grained notion that can serve to analyse metaphysical necessity. ${ }^{9}$

If one acknowledges the inadequacy of the modalist account of essence, there is much to recommend in a reduction of necessity to essence. This is because one cannot do without essences in forming a coherent view of reality. It seems incoherent to believe that one can speak about and refer to things if one does not at least believe that those things have identities, whether known to them or not, that make reference

\footnotetext{
9 In addition to Fine's counterexamples, another objection to classical modalism is that it gets the direction of explanation the wrong way. It is what things are, their essences, that can explain how they must be and not the other way around as the classical modalist implies. Thanks to an anonymous reviewer for pressing me to outline an additional justification for the rejection of classical modalism.
} 
and thought be about them and not about other things. It is this notion of identity that corresponds to the notion of essence as used in this paper. ${ }^{10}$

If we cannot do without essences, it is therefore interesting to make essences do as much work, in our metaphysical theorizing, as we can make them do. This would allow us to limit the number of fundamental posits in our theories, as good methodological practices require. So, if metaphysical necessity can be reduced to essence, one should not shy from endorsing such a reduction. This is what several philosophers did.

A popular reduction of necessity to essence proposed by Fine is that a fact $P$ is necessary if and only if it obtains in virtue of the nature of some plurality $x x$ of things. ${ }^{11}$ As for possibility, recourse to pluralities enables us to capture the necessity of some facts that do not obtain in virtue of the nature of any given member of a certain plurality but obtain in virtue of the natures of these members taken collectively. An example would be the alleged necessary distinctness of Socrates and the Eiffel Tower which does not hold in virtue of the essence of any of these objects taken in isolation but in virtue of their essences when considered collectively. ${ }^{12}$

This classical reduction of necessity to essence raises some worries related to the inclusion of actual contingent and merely possible objects in the domain whose members ground necessary facts in virtue of their essences (merely possible objects are those, if any, that are possible but not actual). Recent objections to the reduction of necessity to essence are mainly based on uncovering some paradoxes or contradictions that result from the project of reducing necessity to essence while allowing that contingent and merely possible objects are among those whose natures ground necessary facts (Teitel, 2019; Wildman, 2021). To avoid these objections, I propose the following reduction of necessity to essence.

Metaphysical necessity (essentialist reading): a fact $F$ is necessary if and only if it obtains in virtue of the essence of some plurality $x x$ of independent beings.

This modified reduction of necessity to essence restricts the domain of objects or beings whose natures ground metaphysical necessities to that of independent beings. I mean by an independent being a being that exists in virtue of what it is, in virtue of its essence. If there are independent beings, my modified definition of metaphysical necessity ensures that they exist necessarily.

The main motivation behind this restriction of the domain of beings whose natures ground metaphysical necessities is prohibiting the inconsistent requirement that the natures of some contingent or merely possible beings ground metaphysical necessities that are true even in possible worlds where those beings do not exist (I appeal to possible worlds only as a useful tool for convenience and ease of exposition without any ontological commitment related to their existence).

When it comes to the abstract realm, some might think that it is beyond doubt that there are necessary truths about abstract objects. For example, it is widely held that mathematical truths such as $1+1=2$ are necessary. On my view of metaphys-

\footnotetext{
10 A similar point about the indispensability of essence is made in Lowe (2018).

11 I translate Fine's talk about propositions to talk about facts for consistency with the current exposition.

12 I say that this is an "alleged" necessity because I do not take it to be a metaphysical necessity in the absolute unrestricted sense. Socrates and the Eiffel tower are contingent beings, their distinctness does not hold when one of them does not exist.
} 
ical necessity, such truths, if they are to qualify for necessity, must be grounded on the natures of abstract mathematical objects that are independent beings. Taking this observation into account and given that they are causally inert and do no harm, I am happy by courtesy, to give abstract beings the privilege of counting among the independent beings whose natures ground metaphysical necessities. I allow then, for our current purposes, independent beings to be either concrete or abstract.

Given my two definitions of metaphysical necessity that must be equivalent for consistency, I am then committed to the following claim.

A fact $F$ obtains in virtue of the nature of some plurality $x x$ of independent beings if and only if $F$ obtains and there is no plurality yy of actual beings with iterated causal powers to bring about the non-obtaining of $F$.

The left to right conditional is quite straightforward. If a fact $F$ obtains in virtue of the essence of some plurality $x x$ of independent beings, then there is no power to bring about the non-obtaining of $F$. This is because independent beings exist in virtue of their essences and therefore cannot fail to exist, which ensures that there is no power to bring about that an independent being does not exist. If one observes that the existence of independent beings entails the obtaining of whatever obtains in virtue of their essences, in every circumstance where they exist, which cover all possible circumstances, one can then conclude that as there is no power to bring about the nonexistence of independent beings, there is no power to bring about the non-obtaining of any fact that obtains in virtue of their natures.

What about the right to left conditional? It is useful to reason about its converse that is.

A fact $F$ does not obtain in virtue of the essences of any plurality of independent beings if $F$ does not obtain or there is a plurality $x x$ of actual beings with iterated causal powers to bring about the non-obtaining of $F$.

If $F$ does not obtain, there is no difficulty in securing the truth of the conditional. If $F$ obtains and not so in virtue of the nature of some plurality of independent beings, its obtaining rests either at least partially on the existence of some dependent beings, their properties and relations or it rests exclusively on non-essential facts about some independent beings, their properties and relations. In the former case, it is plausible to suppose that some of the beings on whose existence, properties and relations the obtaining of $F$ rests can possibly fail to exist. In such a case, $F$ would have failed to obtain. The causal powers that ensure the possibility of the non-existence of the beings on which the obtaining of $F$ depends are powers to bring about the non-obtaining of $F$. In the last case to consider, $F$ 's obtaining rests on accidental features of independent beings that could have failed to obtain, leading to the non-obtaining of $F$. The required causal powers to bring about the non-obtaining of $F$ lie within the independent beings on whose properties and relations its obtaining rests. ${ }^{13}$

With the notion of efficient causation and my account of modality on board, let us move on to the exposition of the argument for the causal fundamentality.

\footnotetext{
13 There is here an assumption that independent beings have the powers to bring about any pattern of instantiation of accidental properties by them. This assumption is worth making to preserve the duality of necessity and possibility.
} 


\section{The argument}

My argument for causal fundamentality is a reductio ad absurdum of the hypothesis that the actual world contains a being whose causal history does not include any uncaused (fundamental) being. The causal history of some being $x$ is the class of all its efficient causes.

The argument can be presented as follows:

(1) If there is an actual being $x$ such that every chain in its causal history $H$ is infinite, then there is a possible world $W$ where x's having causal history $H$ is not possible (premise).

(2) What is actual is necessarily possible (Brouwer axiom, premise).

(3) If there is an actual being $x$ such that every chain in its causal history $H$ is infinite, then there is no possible world $W$ where x's having causal history $H$ is not possible [from (2), contradiction with (1)].

Therefore,

(4) There is no actual being $x$ such that every chain in its causal history $H$ is infinite (i.e. every actual being has at least one (uncaused) fundamental being in its causal history).

The idea behind the argument is the following. Assume, for the sake of argument, that the actual world contains a being $x$ such that every chain in its causal history $H$ is infinite. Then observe that $H$ is causally closed. No being that is not in $H$ is an efficient cause of some being in $H$. To exploit this characteristic of $H$, I propose to bring the proponents of such a causal history, assuming that they do not mind, to a possible world $W$ where none of the members of $H$ exist. It turns out that, from this world, we cannot get to any world containing $x$ with causal history $H$ because nothing in $W$ has the causal power to bring about that $x$ has $H$ as causal history (any causal action to bring about the existence of $x$ would result in it having a causal history other than $H$ ). In other words, x's having causal history $H$ is impossible in $W$. However, $x$ actually has causal history $H$ and what is actual is necessarily possible, meaning that x's having causal history $H$ is, after all, possible in $W$. This contradiction, x's having causal history $H$ being both possible and impossible in $W$, enables us to conclude that the starting hypothesis, the actual existence of a being such that every chain in its causal history is infinite, is false. This in turn, shows that every caused being has at least one (uncaused) fundamental being in its causal history.

The argument is valid and has two premises (1) and (2). Among the two premises, (2) is the well-known Brouwer axiom that many philosophers take to be an unnegotiable principle that governs metaphysical modality. This gives some prima facie assurance that it is a safe basis for the argument. Premise (1) seems then to be the key premise of the argument.

In the next section, I will go beyond mere intuitions and defend premises (1) and (2) based on my account of metaphysical modality. 


\section{Defending the premises}

\subsection{A defence of premise (1)}

Premise (1) asserts that on the supposition that the actual world contains a being $x$ such that every chain in its causal history $H$ is infinite, there is a possible world $W$ where x's having causal history $H$ is not possible.

One such world is one in which none of the members of $H$ exist. Taking advantage from the dual definitions linking possibility and necessity, we can show that it possible that none of the members of $H$ exist by showing that it is not necessary that some of the members $H$ exist.

For it to be the case that it is necessary that some of the members of $H$ exist, it must hold in virtue of the essences of some plurality of independent beings that some of $H$ 's members exist. To see that this cannot be the case, let us start by observing that none of the members of $H$ is an independent being. This is because each of the members of $H$ exists because it is caused to exist and does not therefore exist in virtue of its essence.

Once we have seen this, it becomes clear that all independent beings lie outside $H$. If we recognize further that there is nothing in the essences, the real definitions, of the independent beings that are all external to $H$, that necessitates the existence of some members of this causal history, we arrive to the conclusion that it is not true in virtue of the essences of any plurality of independent beings that some of the members of $H$ exist. ${ }^{14}$ This licences the intended result that it is possible that none of the members of $H$ exist.

Now, there is a possible world $W$ that contains none of the members of the supposed causal history $H$. From the standpoint of $W$, the possibility of x's having causal history $H$ is conditional on the existence in this world of some plurality of beings with iterated causal powers to bring about that $x$ has this causal history.

Could there be such a plurality of beings with the needed powers to make $x$ have $H$ as causal history? The answer is no. Any causal action, starting from $W$, to bring about the existence of $x$ would guarantee that it has a causal history other than $H$. This is true because no being in $W$ is part of $H$. Therefore, starting from $\mathrm{W}$, any possible world that contains $\mathrm{x}$ will contain it with a causal history other than $H$.

This being so, it follows that x's having causal history $H$ is not possible in $W$.

\subsection{A defence of premise (2)}

Premise (2), the Brouwer axiom that ensures the symmetry of the accessibility relation between possible worlds, can be derived from my account of modality in the following way.

\footnotetext{
14 I am happy to allow that it might be the case that no real definition of some being $x$ can be given without including a being $y$ on which $x$ ontologically depends. What I deny is that the real definition of a being $x$ includes beings on which it does not ontologically depend. Given that no independent being ontologically depends on some members of $H$, it is not true in virtue of the nature of any independent being that some members of $H$ exist.
} 
Were the exercise of some causal powers different from what it is, in the actual world, leading to another world $W$ being actualized, it would have remained true in $W$ that it is within the powers of actual beings to exercise their powers as they actually did. This reasoning is valid given that the causal powers that beings have do not depend on which powers they actually exercise. Pruss notes, when defending his Aristotelian account of modality, that "It is important that what the powers of an item (state of affairs or substance) at $t$ are, the actualization of which powers grounds various possibilities, should not itself depend on which of these powers are actualized. For then the powers would not be prior to the actualization." (Pruss, 2001).

This shows that premise (2) is well justified given the account of modality under which the argument is developed.

\section{The commitment to independent beings}

We have seen how my account of metaphysical modality supports causal fundamentality. The strength of the overall support gained by this thesis is of course dependent on the standing of my modal account as a serious competitor of other popular accounts of modality. One main worry would be that the hybrid dispositional-essentialist foundation of my account makes it lose in parsimony in comparison with purely essentialist and dispositionalist theories of modality that have less fundamental posits. It is beyond the scope of this paper to provide a full defence of the merits of my modal account, but I can say that the interplay between essences and powers should allow it to do honourably well in addressing the classic objections levelled against modal essentialism and dispositionalism. Moreover, I think that, ultimately, an essentialist foundation of powers may be within reach. If powers are grounded in essences, there would be only one fundamental posit in my account, which is essences. But this is another story that I have to leave for another occasion.

My aim in this section is rather modest. My account of metaphysical modality carries in it a commitment to the existence of concrete (independent) necessary beings that some might find problematic because they hold that all concrete beings are contingent. I would like to argue that this is no extra cost of my account in comparison with standard essentialist and dispositionalist accounts of modality.

Let us first see how a commitment to the existence of independent beings emerges from my modal account. To do so, let us start by considering the fact $E$ 'something concrete exists'. Given that something concrete exists actually, it turns out that $E$ is necessary on my modal account. This is so given that the supposition that it is possible that $E$ does not obtain is incompatible with dispositionalist accounts of possibility such as the one I am committed to. The argument for this incompatibility can be given as follows.

a. If an empty world is accessible from the actual world, then the actual world is accessible from that empty world (premise).

b. The actual world is not accessible from any empty world (premise). Therefore,

c. No empty world is accessible from the actual world. 
An empty world is one in which nothing concrete exists.

The argument given in Sect. 4.2 shows that dispositional accounts of possibility are committed to Brouwer's axiom. Premise (a) is an application of this axiom that entails that the accessibility relation between possible worlds is symmetric. Premise (b) is a direct consequence of the dispositionalist requirement that possibility depends on being. In an empty world, there is nothing with iterated power to bring about the existence of something concrete. It is thus impossible for there to be something concrete, as it is actually the case, from the standpoint of an empty world. This means that, as premise (b) states, that the actual world is not accessible from any empty world. ${ }^{15}$ One can then conclude that, given that something concrete exists, it is necessary that there are concrete beings.

On my modal account, the necessity of there being something concrete is so in virtue of the essences of some plurality of independent beings. This can be so only if there are, actually, concrete independent beings. It follows then that my account of modality carries in it a commitment to the existence of necessary (independent) concrete beings.

What about purely dispositionalist accounts of modality? Do they support a commitment to the existence of necessary concrete beings? To answer this question, I will rely on the previous result that dispositionalist accounts of possibility are committed to the necessity of there being something concrete. If dispositionalists were to insist that all concrete beings are contingent, their view would have the bizarre consequence that the non-existence of some contingent concrete beings necessitates the existence of other contingent beings. It is hard to see how such a commitment can be made plausible under a purely dispositionalist account of modality. It seems then that the best move for dispositionalists is to accept the existence of necessary concrete beings, which makes their view on a par with mine when it comes to the specific consideration regarding the commitment to necessary concrete beings.

When it comes to standard modal essentialism à la Fine (1994), it seems that it is already committed to necessitism, the view that everything exists necessarily, and $a$ fortiori to the necessary existence of all concrete beings. Assuming that it is essential to Socrates to be human, on standard modal essentialism, the fact that 'Socrates is human' is necessary. This could not be the case if it was possible that Socrates does not exist. $^{16}$

One can then conclude that a commitment to necessary concrete beings can hardly be escaped by some of the most serious competitors of my hybrid account of metaphysical modality and that such a commitment is not, after all, a cost that is specific to my own account.

\footnotetext{
15 Concrete beings are those that can enter into causal relations. Abstract beings are those that cannot enter into causal relations and cannot bring about the existence of something concrete.

16 Teitel (2019) presents an interesting argument that supports further the conclusion that modal essentialism is committed to necessitism.
} 


\section{Conclusion}

I have given an argument for causal fundamentality understood as the thesis that the causal history of every being, whose existence has a causal explanation, includes some uncaused beings. The premises of the argument are consequences of the account of metaphysical modality on which it relies.

A main motivation behind my modal theory is a return to basics about modality as captured in the pre-theoretical meaning of metaphysical necessity and possibility. I contend that my theory is, to its advantage, extensionally correct and minimalistic. Its range of metaphysical necessities and possibilities is just as wide as needed to capture the pre-theoretical notion of modality. Furthermore, my theory is immune from the necessitism of standard essentialist accounts of modality and addresses the challenge of global possibilities facing dispositionalist modal theories thanks to its essentialist component. Finally, my theory's commitment to independent beings does not speak against it in comparison with purely dispositionalist and essentialist modal accounts given that those, if they are to retain their plausibility, must be committed as well to the existence of necessary concrete objects.

Regarding the question of causal fundamentality, mere intuition was usually the sole basis on which arguments for this thesis were built. Meyer nicely summarizes the traditional line of argument against infinite causal regression (which, if successful, entails causal fundamentality).

Everything has a cause. And the cause of everything has a cause. So metaphysics teaches. Project any of these causal sequences indefinitely back, without limit, and the mind boggles. Whence there is a First Cause. (Meyer, 1987, p. 345).

Turning this simple intuition to a cogent argument has not been, as far as I know, a success. Aquinas, to take a famous example, hardly escapes circular reasoning in his Second Way for the existence of God when he argues that "if there be no first cause among efficient causes, there will be no ultimate, nor any intermediate cause." (Aquinas, 2006).

Nowadays, things do not seem so different. A recent example is Schaffer who argues for ontological foundationalism relying on the intuition that, in the absence of some ontologically fundamental level, "being would be infinitely deferred, but never achieved" (Schaffer, 2010, p. 62).

To move beyond mere intuitions and avoid the charge of question-begging, I proposed a different kind of argument that exploits the recent advances in our understanding and theorizing about causality, essence, and modality, to propose a modal theory that can be considered seriously given its advantages and that speaks directly for causal fundamentality. I hope that this work will pave some new paths to explore regarding the lively debates about causal fundamentality and theories of modality.

Acknowledgements Thanks to Yujin Nagasawa and Alastair Wilson for their detailed comments on multiple drafts of this article. I am grateful to two anonymous reviewers for Synthese for feedback that led to improvements. Previous versions of this article have been presented at the universities of Birmingham, Durham and Geneva. Thanks to the audiences at these universities for their comments and feedback. Special thanks to Claudio Calosi, Fabrice Correia, Giacomo Giannini, Salim Hireche, Giovanni Merlo, Robert Michels, Maria Scarpati, Andy Thomas, Marcus Ventin and Lisa Vogt. 
Open Access This article is licensed under a Creative Commons Attribution 4.0 International License, which permits use, sharing, adaptation, distribution and reproduction in any medium or format, as long as you give appropriate credit to the original author(s) and the source, provide a link to the Creative Commons licence, and indicate if changes were made. The images or other third party material in this article are included in the article's Creative Commons licence, unless indicated otherwise in a credit line to the material. If material is not included in the article's Creative Commons licence and your intended use is not permitted by statutory regulation or exceeds the permitted use, you will need to obtain permission directly from the copyright holder. To view a copy of this licence, visit http://creativecommons.org/licenses/by/4.0/.

\section{References}

Aquinas, T. (2006). Summa Theologica, Part I (Prima Pars) From the Complete American Edition. Project Gutenberg. http://www.gutenberg.org/ebooks/17611

Bliss, R. (2019). What work the fundamental? Erkenntnis, 84(2), 359-379.

Borghini, A., \& Williams, N. E. (2008). A dispositional theory of possibility. Dialectica, 62(1), 21-41.

Fine, K. (1994). Essence and modality. Philosophical Perspective, 8, 1-16.

Fine, K. (2001). The question of realism. Philosophers' Imprint, 1, 1-30.

Hale, B. (2018). The basis of necessity and possibility. Royal Institute of Philosophy Supplement, 82, $109-138$.

Leftow, B. (2017). The nature of necessity. Research Philosophica, 94(3), 359-383.

Lewis, D. (1986). Events. II. Oxford University Press.

Lowe, E. J. (2013). A modal version of the ontological argument. In J. P. Moreland, K. A. Sweis, and C. V. Meister (Eds.), Debating Christian Theism. Oxford University Press.

Lowe, E. J. (2018). Metaphysics as the Science of Essence. In Alexander Carruth, Sophie Gibb, \& John Heil (Eds.), Ontology, Modality, and Mind: Themes from the Metaphysics of E. J. Lowe. Oxford University Press.

Meyer, R. K. (1987). God exists! Noûs, 21(3), 345-361.

Pruss, A. (2001) Possible Worlds: What They Are Good for and What They Are. Dissertation. University of Pittsburgh.

Rosen, G. (2015). Real definition. Analytic. Philosophy, 56(3), 189-209.

Schaffer, J. (2010). Monism: The Priority of the Whole. Philosophical Review, 119(1), 31-76.

Tahko, T. E. (2018). Fundamentality. The Stanford Encyclopedia of Philosophy: Fall 2018 Edition. Edward N. Zalta (ed.). https://plato.stanford.edu/archives/fall2018/entries/fundamentality/

Teitel, T. (2019). Contingent existence and the reduction of modality to essence. Mind, 128(509), 39-68.

Torza, A. (2015). Speaking of essence. Philosophical Quarterly, 65, 754-771.

Vetter, B. (2015). Potentiality: From Dispositions to Modality. Oxford: Oxford University Press.

Wildman, N. (2021). Against the reduction of modality to essence. Synthese, 198(Suppl 6), 1455-1471.

Wilson, A. (2018). Metaphysical causation. Nô̂s, 52, 723-751.

Yates, D. (2015). Dispositionalism and the modal operators. Philosophy and Phenomenological Research, 91(2), 411-424.

Publisher's Note Springer Nature remains neutral with regard to jurisdictional claims in published maps and institutional affiliations. 